\title{
Hydrogen-carbon dioxide anomaly within the boundaries of the "Holy Nose" ring ice structure formation (Svyatoy Nos Peninsula)
}

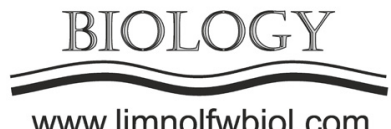

www.limnolfwbiol.com

\author{
Iakovlev D.V. ${ }^{1 *}$, Isaev V.P. ${ }^{2}$, Petrov V.V. ${ }^{1}$, Khabarova A.A. ${ }^{1}$, Brylina A.V. ${ }^{1}$ \\ ${ }^{1}$ A. P. Karpinsky Russian geological research institute» (VSEGEI), Sredny pr. V.O., 7 4, St. Petersburg, 199106, Russia \\ ${ }^{2}$ Baikal center», Dekabrskih sobytii st., 29, Irkutsk, 664007, Russia
}

\begin{abstract}
Unique H2-CO2 anomaly was revealed in April of 2016 as a result of gas-hydrochemical sampling of water-soluble gases of near-surface waters within the boundaries of «Holy Nose» ring ice structure (near N. Izgolovye cape, Svyatoy Nos Peninsula), which is previously known and described in 2016 by Kouraev K.V. et al. The composition of the anomaly - volumetric content of $\mathrm{H} 2$ is from 25.8 to $48.8 \%$ vol., $\mathrm{CO} 2$ is from 11.4 to $16.9 \%$ vol.; depth at the sampling point $\sim 1500 \mathrm{~m}$.
\end{abstract}

Keywords: Ring ice structures, RIS «Holy Nose», Lake Baikal, hydrogen, the Svyatoy Nos Peninsula.

\section{Materials and methods}

The external morphology of the ring structure has changed significantly to the time of the survey on 11.04.2016 since its first occurrence on 14.04.2016 (dynamics of change in Kouraev et al., 2019). The object was a round-shaped area $\sim 7 * 8 \mathrm{~km}$ in size (slightly elongated in the NE direction). In the northern part of the area, there was open water; the southern part was occupied by accumulated crushed ice collected in a corner by the wind from the rest of the area. Around the structure, there were many cracks, thinning of ice when approaching the edge of the ring.

A joint group of specialists from VSEGEI and «Baikal Center» selected 13 water samples in nearsurface conditions from two profiles. Sampling was carried out using a «Hivus»-type hovercraft. The first profile is $700 \mathrm{~m}$ long in the SE edge; the second profile is about $7 \mathrm{~km}$ long from the SE edge through the center toward to NW edge of the ring structure. Thermal degassing of water was carried out the next day: the gas was collected in upside-down glass vials $(30 \mathrm{ml})$, which were preserved by the salt brine, a rubber stopper, and a plastic cap. A gas chromatographic analysis was performed 14 days later at «Sibgeocom» (Irkutsk) on a Chromos GH-1000 (Fig. 1D).

\section{Conclusions}

1. 4 out of 13 water-soluble gas samples showed a simultaneous overestimation of the $\mathrm{H}_{2}$ content from 25.8 to $48.8 \%$ vol. and $\mathrm{CO}_{2}$ from 11.4 to $16.9 \%$ vol. (at average values for surface waters 0.0005 and 1.5\% vol. respectively) against the background of a reduced $\mathrm{O}_{2}$ content from 4.8 to $10.5 \%$ vol. (average $23 \%$ vol.) (Fig. 1A).

2. Hydrocarbons are contained in the watersoluble gases in the background content. Moreover, in this area, sources of the visible discharge of hydrocarbons (mud volcanoes, gas flares, gas hydrates, etc.) are unknown.

3. The revealed anomaly was not confirmed during the research of dissolved gas of the bottom water

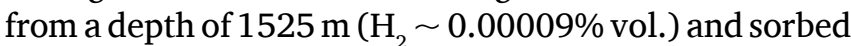
gas of bottom sediments $\left(\mathrm{H}_{2} \sim 0.00008 \%\right.$ vol. $)$ received in this area by VSEGEI specialists from the board of the R/V Vereshchagin in July 2016 (by Shakhverdov V.A.). However, due to geophysical studies (CSP) in July 2019 (by Shakhverdov V.A.), VSEGEI specialists revealed a bottom tectonic structure. (Fig. 1C).

4. Repeated studies in April of 2018 (similar to those carried out in 2016) showed that the contents of $\mathrm{H}_{2}, \mathrm{CO}_{2}$, and $\mathrm{He}$ did not exceed background concentrations.

5. The most appropriate principle for the formation of a water-soluble gas anomaly of this type was proposed in conjunction with doctor of Geological and Mineralogical Sciences Isaev V.P. (Fig. 1B). We assume that an unknown volume of a portion of a hydrothermal fluid saturated with mantle components $\left(\mathrm{H}_{2}, \mathrm{CO}_{2}\right.$, and $\left.\mathrm{He}\right)$ with a hard to predict mode is dispersed into the water area of the lake through the sedimentary sequence through deep faults. On the path of vertical migration, $\mathrm{H}_{2}$ enters an exothermic reaction 
with $\mathrm{O}_{2}$ dissolved in water. As a result, relatively warm and slightly mineralized water can form, which in turn during the ice period can lead to the formation of a ring ice structure.

\section{Reference list}

Galimov E.M. 1973. Isotopy ugleroda $\mathrm{v}$ neftegazovoj geologii. [Carbon isotopes in oil and gas geology.] Publ. «Nauka». (in Russian)
Kouraev K.V., Zakharova E.A., Rémy F. et al. 2016. Giant ice rings on Lakes Baikal and Hovsgol: inventory, associated water structure and potential formation mechanism. Limnology and Oceanography 61: 1001-1014. DOI: 10.1002/ lno.10268

Kouraev K.V., Zakharova E.A., Rémy F. et al. 2019. Giant ice rings on lakes and field observations of lens-like eddies in the Middle Baikal (2016-2017). Limnology and Oceanography 64: 2738-2754. DOI: 10.1002/1no.11338
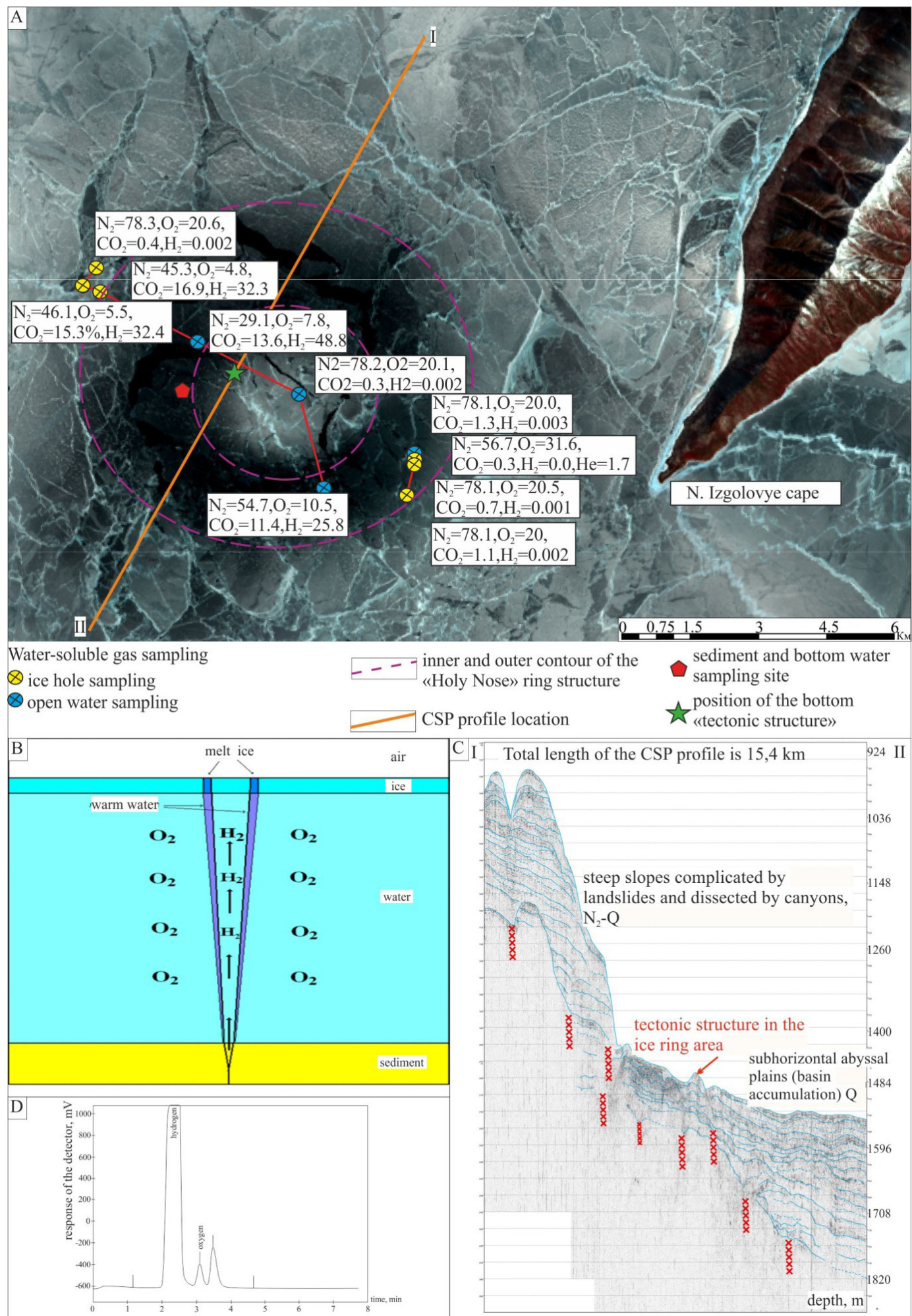

Fig.1. Some research results of the «Holy Nose» ring ice structure: A - results of research of dissolved gases of near-surface waters within the boundaries of the ring ice structure "Holy Nose" on 11.04.2016 (an earlier Landsat-8 image from 1.04.2016 was used as a substrate); B -schematic model of the formation of the «Holy Nose» ring ice structure; C - CSP profile shown in Fig. $1 \mathrm{~A}$; D - gas chromatogram example $\left(\mathrm{H}_{2}=48.8 \%\right.$ vol. $)$ 